\title{
First records and human activity on Brazilian Atlantic Forest Dictyostelids
}

\author{
Xavier de Lima $V^{1 *}$ \\ ${ }^{1}$ Universidade Federal de Pernambuco, Centro de Ciência Biológicas, Departamento de Micologia, Programa de Pós- \\ Graduação em Biologia de Fungos, Av. Prof. Moraes Rego, 1235, 50670-901. Recife, Brazil
}

Xavier de Lima V 2013 - First records and human activity on Brazilian Atlantic Forest Dictyostelids. Mycosphere 4(3), 584-589, Doi 10.5943/mycosphere/4/3/11

\begin{abstract}
Dictyostelid cellular slime moulds isolated from two natural and cultivated areas in lowland Atlantic Forest of northeastern Brazil were identified and quantified. Nine species were recognized: Dictyostelium fasciculatum, D. firmibasis, D. macrocephalum, D. aff. monochasioides, D. mucoroides, D. purpureum, Polysphondylium pallidum, P. pseudocandidum and P. violaceum, which are the first records for Brazil. The most abundant species were D. mucoroides, $D$. purpureum and $P$. pallidum. A decrease in the abundance of dictyostelids was observed in cultivated areas, indicating that this organism responds to human disturbance.
\end{abstract}

Key words - anthropization - cellular slime moulds - Pernambuco State - soil biota

\section{Introduction}

Dictyostelids are bacterivorous amoebae able to aggregate into pseudoplasmodia and form macroscopic fruiting bodies (Raper 1984). They mainly inhabit the soil where they can be found in extremely high populations (Vadell et al. 2011), but are also recorded in other habitats like dung and organic debris that becomes trapped in trees (Raper 1984, Stephenson \& Landolt 1998). Considering the wide global distribution and their abundance in different microhabitats, these organisms probably have a strong impact on bacterial populations.

The three genera and over 120 species known in the group are recorded occurring in different ecosystems and continents, but there are still large areas where no studies have been conducted (Swanson et al. 1999). In South America, they have already been studied in Peru, Uruguay, Argentina and Chile (Swanson et al. 1999, Vadell 2000, Vadell \& Cavender 2007, Vadell et al. 2011). They were explored in parts of the Amazon forest of Brazil and in the southernmost region, but these results were never published (Swanson et al. 1999).

This study provides the first information about dictyostelid cellular slime mould species occurring in Brazilian natural Atlantic Forest and cultivated areas in the state of Pernambuco, Northeastern Brazil.

\section{Methods}

Eight soil samples were collected in two fragments of lowland Atlantic Rain Forest located in the state of Pernambuco - the Charles Darwin Ecological Refuge (60 ha, municipality of Igarassu, 07² $48^{\prime} 55.9^{\prime \prime S} 034^{\circ} 57^{\prime} 16.9^{\prime \prime} \mathrm{W}, 50 \mathrm{~m}$ ) and the Ecological Reserve of Carnijó (135.5 ha, 
municipality of Moreno, $08^{\circ} 08^{\prime} 47.6^{\prime \prime S} 03^{\circ} 504^{\prime} 32.6^{\prime \prime} \mathrm{W}, 120 \mathrm{~m}$ ). Although disturbed, these remnants of Brazilian Atlantic Forest have a closed canopy up to $15 \mathrm{~m}$ above ground (Pietrobom \& Barros 2003), with a thick layer of leaf litter, which is moist for about 10 months a year. Two monocultures were chosen, manioc (Manihot esculenta Crantz, Euphorbiaceae) and sugarcane (Saccharum officinarum L., Poaceae), in an area located at the municipality of Cabo de Santo Agostinho $\left(8^{\circ} 15^{\prime} 17.00^{\prime \prime} \mathrm{S} 35^{\circ} 03^{\prime} 37.03^{\prime \prime} \mathrm{W}, 70 \mathrm{~m}\right)$, about $20 \mathrm{~km}$ distant from the two protected areas. The two growing areas receive natural fertilization and are regularly treated with pesticides. Four soil samples were collected from each culture. The predominant soil type in this area is latosol and podzol (IBGE 1992). In this region of the state of Pernambuco, the average annual rainfall is 2400 $\mathrm{mm}$. The weather fits in As' of Koppen's classification, with average temperatures between 23.8 to $26.5^{\circ} \mathrm{C}$ throughout the year.

After the removal of the outermost layer of litter, where the leaves are still nearly undamaged, the soil sample was collected with the aid of a sterile spoon. At each sampling site, random samples were collected at four points, $1 \mathrm{~m}$ apart from each other, and assembled to form a compound sample (about $30 \mathrm{~g}$ ), which was wrapped in a plastic bag for transportation to the laboratory.

The methodology for cultivation was based on Cavender \& Raper (1965). Each soil sample was placed in an Erlenmeyer flask and sterile distilled water was added to reach a dilution of 1:25 and then the container was shaken vigorously. Half milliliter of this suspension (0.02 $\mathrm{g}$ soil) was placed into three Petri dishes containing hay infusion agar, with $0.5 \mathrm{ml}$ of a heavy suspension of Escherichia coli. The cultivation continued at room temperature $\left(22-24{ }^{\circ} \mathrm{C}\right)$, receiving fluorescent light indirectly in a cycle of approximately 12 hours. Each Petri dish was examined daily for aggregations or sorocarp formation for a period of two weeks. The specimens obtained were isolated in a Petri dish containing non-nutrient agar with a suspension of $E$. coli for life cycle observation and specie identification.

\section{Results}

All sampled areas revealed the presence of dictyostelids (Table 1). In environments of dense lowland rain forest and cultivation of manioc and sugarcane two genera and nine species were recorded, with an average of 50.3 clones per gram of soil. Below are presented commentaries on morphology and area of record for each species found.

Dictyostelium fasciculatum Traub, M. Hohl \& Cavender (manioc)

Sorocarps delicate, in groups, up to $5 \mathrm{~mm}$ in height. Spores ellipsoid with conspicuous consolidated polar granules. A characteristic of this species is the variation of aggregation forms. In the single specimen found was observed two forms of aggregation described by Raper (1984): one is the formation of a large, flat aggregate, where in the periphery can be seen multiple streams of amoebae; during development fragmentation occurs, forming several independent centers where one or few sorocarps are formed. The second type of aggregations are also flattened, but smaller, centralized and no fragmentation occurs, various sorocarps rise from the same center.

Outside Europe, this species is registered in New Zealand (Cavender et al. 2002) and North America (Landolt et al. 2006). This is the first record of this species for the tropical region.

Dictyostelium firmibasis $\mathrm{H}$. Hagiw. (sugarcane)

Very similar to $D$. giganteum Singh, but easily recognizable by the larger size of the spores (average of $7.5 \times 3.2 \mu \mathrm{m}$ ) with an elongated appearance, and the yellowish shade of its sori.

Hagiwara (1989) notes that this species is rare in warmer regions, but has been found in southern Europe (Romeralo \& Lado 2006) and there is also a possible record in Peru (Landolt \& Stephenson 1991). 
Table 1 Number of clones per gram of soil, species frequency and soil sample $\mathrm{pH}$ where each species of dictyostelids were recorded

\begin{tabular}{|c|c|c|c|c|c|}
\hline Species & $\begin{array}{l}\text { Clone/g } \\
\text { Natural }\end{array}$ & Cultivated & Total & Frequency & pH of occurrence \\
\hline Dictyostelium fasciculatum & - & 10 & 10 & 1 & 6.3 \\
\hline D. firmibasis & - & 25 & 25 & 1 & 6.0 \\
\hline D. macrocephalum & - & 70 & 70 & 2 & 6.3 \\
\hline D. aff monochasioides & - & 20 & 20 & 1 & 6.3 \\
\hline D. mucoroides complex & 350 & 40 & 390 & 9 & $3.8,4.4,4.6,5.3,5.8,6.2,6.3$ \\
\hline D. purpureum & 95 & - & 95 & 4 & $4.6,6.2,6.3$ \\
\hline Polysphondylium pallidum & 100 & - & 100 & 3 & $3.8,4.4,4.6$ \\
\hline P. pseudocandidum & 75 & - & 75 & 3 & $3.8,5.8,6.2$ \\
\hline P. violaceum & - & 20 & 20 & 1 & 6.3 \\
\hline Richness & 4 & 6 & 9 & & \\
\hline Average sample abundance & 77.5 & 23.1 & 50.3 & & \\
\hline
\end{tabular}

Dictyostelium macrocephalum H. Hagiw., Z.Y. Yeh \& C.Y. Chien (manioc)

This species is characterized by solitary sorocarps, rarely branched, erect, rarely over 2 high, average of $1.7 \mathrm{~mm}$, tapering conspicuously towards the tip. Clavated tip and expanded, generally conical base. Sori white, globose, containing oblong and hyaline spores, with irregularly scattered and usually visible granules, average size of $7 \times 3.8 \mu \mathrm{m}$. Aggregation large mucoroides-type (Hagiwara 1989).

It is a very characteristic species, generally being recognized using a stereomicroscope. Its height, shape and size of the spores and its clavate tip differentiate it from other similar species. It is a tropical species (Swanson et al. 1999).

Dictyostelium aff. monochasioides H. Hagiw. (manioc)

The specimen found is very similar to D. monochasioides, differing in that the tips are acuminate to filiform, rather than being simple capitate to clavate. Aggregations are always in mound-like structures, never forming streams. During sporulation, the sorocarps of the same aggregation are formed asynchronously, the first sorocarp formed is used as support by those that follow, then giving the characteristic monochasium-like branching. This same mound can remain functional for a few days, with amoebae aggregating and forming new sorocarps continuously.

It is typical of tropical regions (Swanson et al. 1999).

Dictyostelium mucoroides Bref. complex. (forest, manioc)

This species complex is characterized mainly by solitary white sorocarps, and spores elliptical to oblong, hyaline, without polar granules. The way in which $D$. mucoroides was described, includes a great variety of forms, some authors consider it variations of a species, and others try to find patterns (Hagiwara 1989). In the present study, we found several specimens that fit the description of $D$. mucoroides, but some, described below, seem to fit the descriptions of species from the concept proposed by Hagiwara (1989):

D. brefeldianum: sorophore tip compound capitate. Spores oblong, on average $6.7 \times 3.6 \mu \mathrm{m}$.

D. pseudobrefeldianum: sorophore tip compound clavate. Spores elliptical, on average $6.9 \times$ $3.7 \mu \mathrm{m}$.

Dictyostelium purpureum Olive (forest, manioc)

One of the most common species of this study. Extremely characteristic, produces large sorocarps, up to $1 \mathrm{~cm}$ erect. It is often found lying on the agar, forming large supportive structures at the point where the sorocarp turns up. Both the sori and most of the sorophore have variable purple colour, often very dark. The tip of the sorophore is compound capitate, rarely simple capitate in smaller sorocarps. Spores elliptical and long, large, average of $7.8 \times 3 \mu \mathrm{m}$ without polar granules. 
The aggregations can reach several centimeters, usually centralized, but in some larger specimens the aggregation can be divided into one of the branches, forming a new center.

Cosmopolitan species, but with some preference for low latitudes (Swanson et al. 1999).

\section{Polysphondylium pallidum Olive (forest)}

Sorocarps slightly phototropic, with branching typical of this genus, usually in dense groups, starting from the same center of a large radial aggregation. Sori white, one on the central axis and others in 3-5 lateral branches per whorl. The main axis and branches tips are acuminate. The branches are approximately $200-300 \mathrm{~mm}$ in length. Spores hyaline, with unconsolidated polar granules, average of $6.8 \times 3.6 \mu \mathrm{m}$.

Cosmopolitan species (Swanson et al. 1999).

\section{Polysphondylium pseudocandidum H. Hagiw. (forest)}

This is part of the $P$. pallidum complex, differing from the previous species in the following respects: finer branches $(100-200 \mu \mathrm{m})$ and the terminal segment of the axis very elongated, often not forming a terminal sorus. Sometimes the terminal segment reaches the lid of the Petri dish. This species has a more delicate appearance when compared to $P$. pallidum, being thinner and with smaller sori. Differs from P. candidum H. Hagiw. by its smaller spores. Responds poorly to light stimuli in sporulation. In Japan, its type locality, tends to occur in warmer regions (Hagiwara 1989). In tropical regions was found in Guatemala (Vadell \& Cavender 1998).

\section{Polysphondylium violaceum Bref. (manioc)}

It is easily distinguished from other species of Polysphondylium by the violet color of the sorocarps. Another important feature is the violaceum-type aggregation (Hagiwara 1989), forming large centralized aggregations, which eventually subdivide, developing several other centers, forming grouped sorocarps. The tip of the sorophore main axis and lateral branches are characteristically clavate. In the specimen found, the polar granules of spores ranged from unconsolidated to consolidated.

Only one record of this species was obtained in the present study. Cosmopolitan, being more common in temperate environments (Swanson et al. 1999).

\section{Discussion}

The first records of dictyostelids in Brazil, obtained from cultivated areas and remnants of Atlantic Forest, are not different from what is already known for tropical regions (Swanson et al. 1999). Among the species found, those that occurred in the greatest number of samples, in decreasing order, are Dictyostelium mucoroides, D. purpureum, Polysphondylium pallidum and $P$. pseudocandidum. These species are cosmopolitan and, except for P. pseudocandidum, are among the most abundant found in different types of environments (Swanson et al. 1999).

The number of clones/g recovered by the study of Landolt \& Stephenson (1991) in the Peruvian Amazon forest is similar to that found in the present study (63 clones/g soil), but is much lower than what is reported for some temperate (Landolt et al. 2006, Vadell et al. 2011) and tropical forests (Cavender et al. 2012).

In Argentina, at the subtropical region of South America, Vadell \& Cavender (2007) also collected in areas of Atlantic forest, finding 27 species, with seven new to science. Among the species found, five are also recorded in this study: Dictyostelium macrocephalum, $D$. monochasioides, D. mucoroides, D. purpureum and Polysphondylium violaceum. Among the 13 species from 30 soil samples collected in Peru (Landolt \& Stephenson 1991), D. monochasioides, D. mucoroides, D. purpureum, P. pallidum, and D. firmibasis, which was considered a synonym of D. mucoroides, also occurred in this study. The three most abundant species found in this study are among the most abundant in moist forests in Mexico, sharing also D. macrocephalum and $P$. violaceum (Cavender et al. 2012). 
There was a significant difference in the number of clones recovered from soils of natural and cultivated areas. At the preserved areas, 620 clones/g were recorded, on the other hand, at the cultivated area, only 185 clones/g were recorded. Studies indicate a positive relationship between plant diversity with diversity of dictyostelids (Cavender et al. 2004), but in this work the number of species found in monoculture was higher, due to only one sample from manioc culture, from which were obtained five species (Dictyostelium fasciculatum, D. macrocephalum, D. monochasioides, $D$. mucoroides, and D. purpureum), and 140 clones/g, being the highest value found in a single sample. Other sample from the same area yielded the only record of Polysphondylium violaceum. Even that the dictyostelid richness in cultivated areas are slightly higher, the populations found are small and of restricted distribution, being found in only up to two soil samples (Table 1). Interesting to note the distinction between the communities of natural and cultivated areas, sharing only one species, D. mucoroides, but in different abundance. The other three species that occurred in natural areas are also the most abundant of the present study, but were not recorded in cultivated areas. Maybe the dictyostelids found in forest represents a community closer to a climax, with good competitors species. After soil disturbance these strong competitors were removed, allowing other species to proliferate.

Paillet \& Satre (2010), in forests at the French Alps, indicate that factors other than management (e.g. soil $\mathrm{pH}$ ) of a forest are more influential in the composition and abundance of dictyostelids, but a more dramatic human activity does not seems to fit this hypothesis. In this study, no relationship was found between soil $\mathrm{pH}$ and species richness $(\rho=-0017, \mathrm{p}>0.05)$ and abundance $(\rho=-0032, p>0.05)$ of dictyostelids. Stephenson \& Rajguru (2010) found only Dictyostelium sphaerocephalum (Oudem.) Sacc. \& Marchale and D. giganteum in areas of wheat and canola culture in abundance similar to that recovered from cultivated areas in this study. Several reasons may be associated with lower abundance of dictyostelids in areas of cultivation of manioc and sugarcane. In those areas there is not a layer of dead leaves on the ground, as in forest areas, making the soil loose water faster (Rollins \& Stephenson 2012), reducing the amount and richness of bacteria available as food (Stephenson \& Rajguru 2010), which is probably also related to the use of pesticide.

This work corroborates the conclusion of Stephenson \& Rajguru (2010) that dictyostelids are good bioindicators of environment disturbance, after analyzing several works that deal with these microorganisms in disturbed areas. The number of species found in only 16 samples from areas not much favorable for the growth of dictyostelids as farmland and forests in recovery, indicates that there is a high diversity of species to be discovered in this region of Brazil.

\section{Acknowledgements}

This work constitutes part of the author's MSc dissertation, developed in the Postgraduate Program in Fungal Biology of the Federal University of Pernambuco. The author was supported by FACEPE (Fundação de Amparo à Ciência e Tecnologia do Estado de Pernambuco) through a scholarship (proc. IBPG-1116-2.03/10). The author wish to thank Nestor Powell and Leandro Agra for its support on field work logistics and Dr. Laise Cavalcanti for constructive criticism on the manuscript.

\section{References}

Cavender JC, Raper KB 1965 - The Acrasiae in nature I. Isolation. American Journal of Botany 52, 294-296.

Cavender JC, Stephenson SL, Landolt JC, Vadell EM 2002 - Dictyostelid cellular slime moulds in the forests of New Zealand. New Zealand Journal of Botany 40, 235-264.

Cavender JC, Landolt JC, Stephenson SL, Cavender N, Vadell EM 2004 - Comparison of cellular slime mold populations on three Caribbean Islands, including a description of the new species Polysphondylium equisetoides. Systematics and Geography of Plants 74, 243-250. 
Cavender JC, Landolt JC, Suther HB, Stephenson SL 2012 - Dictyostelid cellular slime moulds of Mexico. Mycosphere 3, 336-351.

Hagiwara H 1989 - The taxonomic study of Japanese dictyostelid cellular slime mould. Tóquio, National Science Museum.

IBGE 1992 - Manual Técnico da Vegetação Brasileira. Série Manuais Técnicos em Geociências 1, $1-92$.

Landolt JC, Stephenson SL 1991 - Cellular slime molds from tropical rain forests of Eastern Peru. Cryptogamic Botany 2, 258-260.

Landolt JC, Stephenson SL, Cavender JC 2006 - Distribution and ecology of dictyostelid cellular slime molds in Great Smoky Mountains National Park. Mycologia 98, 541-549.

Paillet Y, Satre M 2010 - The biodiversity of dictyostelids in mountain forests: a case study in the French Alps. Pedobiologia 53, 337-341.

Pietrobom MR, Barros ICL 2003 - Pteridófitas de um fragmento florestal na Serra do Mascarenhas, Estado de Pernambuco, Brasil. Insula 32, 73-118.

Raper KB 1984 - The Dictyostelids. Princeton University Press. Princeton, New Jersey.

Rollins A, Stephenson S 2012 - Myxomycetes associated with grasslands of the western central United States. Fungal Diversity 59, 147-158.

Romeralo M, Lado C 2006 - Dictyostelids from Mediterranean forests of the south of Europe. Mycological Progress 5, 231-241.

Stephenson SL, Landolt JC 1998 - Dictyostelid cellular slime molds in canopy soils of tropical forest. Biotropica, 30, 657-661.

Stephenson SL, Rajguru SN 2010 - Dictyostelid cellular slime moulds in agricultural soils. Mycosphere 1, 333-336.

Swanson AR, Vadell EM, Cavender JC 1999 - Global distribution of forest soil dictyostelids. Journal of Biogeography 26, 133-148.

Vadell EM 2000 - Dictiostélidos (Eumycetozoa) de suelos de Punta Lara, Provincia de Buenos Aires, Argentina. Revista Argentina de Microbiologìa 32, 89-96.

Vadell EM, Cavender JC 1998 - Polysphondylium from forest soils of Tikal, Guatemala. Mycologia 90, 715-725.

Vadell EM, Cavender JC 2007 - Dictyostelids living in the soils of the Atlantic Forest, Iguazú region, Misiones, Argentina: description of new species. Mycologia 99, 112-124.

Vadell EM, Cavender JC, Romeralo M, Edwards SM, Stephenson SL, Baudalf SL 2011 - New species of dictyostelids from Patagonia and Tierra del Fuego, Argentina. Mycologia 103, $101-117$. 